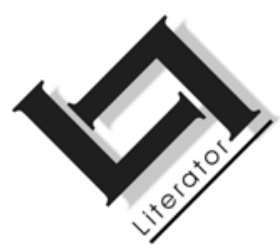

\title{
Die literêre vertaler as kulturele bemiddelaar $^{1}$
}

\author{
M.B. Müller \& I. Feinauer \\ Departement Afrikaans en Nederlands \\ Universiteit Stellenbosch \\ STELLENBOSCH \\ E-pos: margaretbmuller@hotmail.com \\ aef@sun.ac.za
}

\begin{abstract}
The literary translator as a cultural mediator

The translation process is an intercultural transfer that does not only take place between two languages, but between two cultures, as the source and target text are each embedded in a communicative situation in their respective cultures. The literary translator is thus faced with the problem of how to handle the cultural aspects implicit in a source text, and of choosing the most suitable technique to convey these aspects to the target text successfully while keeping in mind the characteristics of the intended readers. The translator can thus be regarded as a cultural mediator who facilitates communication and understanding between people or groups who differ with regard to language and culture.
\end{abstract}

The various culture-specific words and concepts in Dalene Matthee's "Fiela se kind" have far-reaching implications for translation. The extent to which the translator - Matthee herself - succeeded in functioning as a cultural mediator in "Fiela's child" is investigated in this article by means of contrastive analysis. It is argued that a decisive loss of meaning and emotional value occured during the translation process to the detriment of the target text as a literary work. The contention of this article is that Matthee's way of handling translation problems on a microstructural level brought about macrotextual semantic shifts

1 Hierdie artikel is gebaseer op werk gedoen vir die graad M.Phil. in Vertaling (2006). 
in the target text, and that she did not succeed in fulfilling her role as a cultural mediator at all the levels of the text.

\section{Opsomming}

\section{Die literêre vertaler as kulturele bemiddelaar}

Die vertaalproses is ' $n$ interkulturele oordrag wat nie net tussen twee tale plaasvind nie, maar tussen twee kulture, aangesien die bron- en doelteks albei ingebed is in 'n kommunikatiewe situasie in hulle onderskeie kulture. Die literêre vertaler kom dus voor die probleem te staan van hoe om die kulturele aspekte wat implisiet in 'n bronteks is, te hanteer, en om die mees geskikte tegniek te kies om hierdie aspekte suksesvol na die doelteks oor te dra met inagneming van die eienskappe van die beoogde lesers. Die vertaler kan dus as 'n kulturele bemiddelaar beskou word wat kommunikasie en begrip fasiliteer tussen mense of groepe wat verskil ten opsigte van taal en kultuur.

Die verskeie kultuurspesifieke woorde en konsepte in Dalene Matthee se "Fiela se kind" het verreikende implikasies vir vertaling. Die mate waarin die vertaler - Matthee self - daarin slaag om as kulturele bemiddelaar in "Fiela's child" te funksioneer, word in hierdie artikel deur middel van kontrastiewe ontleding ondersoek. Daar word geargumenteer dat 'n deurslaggewende verlies aan betekenis- en gevoelswaarde tydens die vertaalproses plaasgevind het tot nadeel van die doelteks as literêre werk. Die standpunt van hierdie artikel is dat Matthee se hantering van vertaalprobleme op 'n mikrostrukturele vlak makrotekstuele semantiese verskuiwings in die doelteks teweeggebring het en dat sy nie daarin geslaag het om haar rol as kulturele bemiddelaar op alle vlakke van die teks te vervul nie.

\section{Vertaling as interkulturele kommunikasie}

Volgens Snell-Hornby (aangehaal in Katan, 1999:126) is die vertaalproses ' $n$ interkulturele oordrag wat nie bloot tussen twee tale plaasvind nie, maar tussen twee kulture, aangesien die bron- en doelteks elkeen geanker is in 'n kommunikatiewe situasie in hulle onderskeie kulture. Die vertaler kom dus dikwels voor die probleem te staan van hoe om die kulturele aspekte wat implisiet in 'n bronteks is, te hanteer en om die mees geskikte tegniek te kies om hierdie aspekte suksesvol na die doelteks oor te dra.

Die probleme wat die vertaler in hierdie verband moet oplos, hang af van die kulturele en linguistiese afstand tussen die betrokke twee tale (James, 2002:1). Volgens Venuti (2001:468) moet die vertaler 
die kulturele en linguistiese verskille tussen die bron- en doelteks oorkom om dit moontlik te maak vir die vreemde teks (die bronteks) om in die doelkultuur ontvang te word.

Vir die doel van hierdie artikel is besluit om die vertaling van Fiela se kind (Matthee, 1985) in Engels te ondersoek, aangesien die eienskappe van die lesers van die Afrikaanse boek en Fiela's child $\mathbf{2}$ (Matthee, 1987) aansienlik verskil, byvoorbeeld wat betref hulle agtergrondkennis, die herinnering aan sekere ervarings, hulle menings, voorkeure en vooroordele, en hulle linguistiese vaardigheid.

Die artikel fokus op die wyse waarop Matthee as vertaler van Fiela se kind in Engels bepaalde gedeeltes in die bronteks hanteer het in haar poging om 'n eindproduk te skep wat as onafhanklike literêre teks dieselfde funksie in die doelkultuur sou kon verrig as wat die bronteks in die bronkultuur verrig. Die mate waarin sy daarin geslaag het om as kulturele bemiddelaar in Fiela's child op te tree, word dus deur kontrastiewe ontleding ondersoek. Was die strategieë en benaderings wat sy gevolg het, werklik suksesvol om die vele kulturele verwysings wat in die bronteks voorkom, suksesvol vir die doeltekslesers aan te bied?

Die hipotese word gestel dat 'n deurslaggewende verlies aan betekenis- en gevoelswaarde tydens die hantering van kulturele verwysings in die bronteks plaasgevind het, met die gevolg dat die doelteks as literêre werk skade gely het.

\section{Literatuuroorsig}

\subsection{Die rol van die vertaler}

The translator is not the sender of the source-text message, but a text producer in the target culture who adopts somebody else's intention in order to produce a communicative instrument for the target culture document or a target culture document of a source culture communication. (Nord, 1991:11.)

Die vertaler is nie net die ontvanger van die bronteks nie, maar ook die produsent van die doelteks. Dit sluit aan by Venuti (2001:470) se siening dat die boodskap in die bronteks altyd deur die vertaler geïnterpreteer en in die doelteks herskep word, veral in literêre

2 Fiela's child is in die VSA, Engeland, Australië, Kanada, Nieu-Seeland, Indië en Suid-Afrika uitgegee. Vir die doel van hierdie artikel verwys "doeltekslesers" net na buitelandse lesers en nie na Engelssprekende Suid-Afrikaanse lesers nie. 
tekste. Daarom moet die vertaler elke brontekselement nagaan om vas te stel of dit die beoogde kommunikatiewe funksie van die doelteks sal kan vervul soos dit is en of dit aangepas moet word (Nord, 1991:17).

Verder moet die vertaler onder andere die waarde en doel van idiosinkratiese taalgebruik deur karakters bepaal en ook die invloed daarvan op makrostrukture (byvoorbeeld karakterisering) in die bronteks nagaan voordat op ' $n$ vertaalstrategie besluit word. Hierdie vertaalstrategie moet verseker dat die kommunikatiewe waarde van die vertaling sover moontlik ooreenstem met dié van die bronteks (Kruger, 1990:143). Dit het tot gevolg dat geen begrip of uitdrukking in isolasie geïnterpreteer en vertaal mag word nie, maar binne die konteks van die hele teks beskou moet word.

Die vertaler kan dus ook as 'n kulturele bemiddelaar (mediator) beskou word (Katan, 1999:12). Volgens Katan is 'n kulturele bemiddelaar 'n persoon wat kommunikasie, begrip en handeling fasiliteer tussen persone of groepe wat verskil ten opsigte van taal en kultuur. 'n Holistiese benadering tot vertaling beteken dat die vertaler as kulturele bemiddelaar sowel die teks as die konteks, met ander woorde die woorde én die geïmpliseerde verwysingsraamwerk, in ag moet neem.

Waar die vertaler ook die skrywer van die bronteks is, soos in die geval van Fiela se kind en Fiela's child, moet in gedagte gehou word dat hierdie persoon intensief by die skep van die oorspronklike teks betrokke was en as sodanig nie dieselfde afstand van hierdie teks sal kan handhaaf as 'n onafhanklike vertaler nie. Dit kan verreikende implikasies vir die vertaling inhou (vgl. byvoorbeeld die laaste paragraaf van 2.5).

\subsection{Die rol van kultuur in vertaling}

Volgens Katan (1999:17) hou definisies van kultuur verband met eksterne sowel as interne faktore. Met eksterne faktore verwys hy na gedrag (bv. taal, gebare en gewoontes) en produkte (bv. literatuur, folklore, kuns en musiek), terwyl interne faktore na idees (bv. oortuigings en waardes) verwys. Elke aspek van kultuur is met mekaar verbind om 'n verenigde kulturele konteks te vorm wat 'n persoon en sy/haar kultuur identifiseer (Katan, 1999:17).

Newmark (2003:94) definieer kultuur meer spesifiek as die unieke leefwyse van 'n gemeenskap wat 'n spesifieke taal as uitdrukkings- 
middel gebruik. Hierdeur gee hy te kenne dat elke taalgroep sy eie kultuurspesifieke eienskappe het.

Newmark (2003:95) beskou egter nie taal as 'n operasionele komponent of eienskap van kultuur nie, omdat dit volgens hom sou impliseer dat dit onmoontlik is om te vertaal. Hierdie standpunt vorm 'n direkte teenstelling met Vermeer se siening, naamlik dat taal 'n deel van kultuur is (Vermeer aangehaal in James, 2002:2). Vermeer (aangehaal in Nord, 1997:33) definieer kultuur as die volledige stelsel van norme en konvensies, insluitend taal, wat 'n individu as lid van sy/haar gemeenskap moet ken om "soos die ander" te wees, of om in staat te wees om anders te wees. Ook Nord beskou taal as 'n intrinsieke deel van kultuur (Nord, 1997:44). Volgens haar kan taalgebruikers nie anders nie as om op 'n kultuurspesifieke manier op te tree.

Ten spyte van die verskille in opinie of taal 'n deel is van kultuur of nie, is dit duidelik dat hierdie twee begrippe nie van mekaar geskei kan word nie en dat albei aspekte ' $n$ belangrike rol speel tydens vertaling. Die vertaler moet byvoorbeeld kulturele verskille tussen die bronteks- en doeltekslesers met betrekking tot gedrag en kommunikatiewe situasies in ag neem (Vermeer aangehaal in Nord, 1997:33).

Tydens die vertaling van 'n boek soos Fiela se kind het die vertaler dus nie net probleme van 'n leksikale of linguistiese aard nie, maar ook van 'n meer fundamentele aard: die begrip van 'n sosiale, ekonomiese, politieke en kulturele Suid-Afrikaanse konteks, sowel as konnotatiewe aspekte van 'n meer semantiese aard. Dit is onwaarskynlik dat die doelteksleser hierdie aspekte volledig sal kan begryp (James, 2002:5). Ook Venuti (2001:473) is van mening dat 'n doelteksleser se begrip van kulturele aspekte uit die bronkultuur altyd gedeeltelik en onvolledig sal wees en noodwendig sal oorhel na sy/haar plaaslike omgewing en omstandighede, met ander woorde na dít wat vir hom/haar bekend is. Daarom is dit belangrik dat die vertaler nie net die leksikale impak op die doelteksleser in gedagte moet hou wanneer hy/sy tydens vertaling belangrike besluite moet neem nie, maar ook die wyse waarop die doelteksleser moontlik sekere kulturele aspekte sal verstaan (James, 2002:2).

\subsection{Algemene strategieë vir interkulturele kommunikasie}

Wat die vertaling van kultuurspesifieke woorde en begrippe betref, stel Newmark (2003:96) twee teenstellende strategieë voor, naamlik 
oordrag (transference) en komponensiële ontleding (componential analysis).

Volgens Newmark gee oordrag "plaaslike kleur en atmosfeer" deur kulturele name en konsepte te behou. In ooreenstemming hiermee word byna al die name van die karakters in Fiela's child met die Afrikaanse spelwyse behou, byvoorbeeld "Kransie" en "Malie", sowel as die aanspreekvorme "ma" en "pa". Hierdie strategie kan egter in sommige gevalle probleme vir die algemene leserskring veroorsaak, deurdat dit hulle begrip van sekere kulturele aspekte beperk en kommunikasie kan verhinder.

Newmark (2003:83) stel dus ook komponensiële ontleding voor, wat hy as die mees akkurate vertaalstrategie beskryf. Komponensiële ontleding verwyder die "kultuur" uit 'n kulturele woord en lig die boodskap daarvan uit. Hierdie strategie is volgens Newmark (2003: 123) buigsaam, maar ordelik om die talryke leksikale hiate linguisties en kultureel - tussen twee tale te oorbrug. In Fiela's child word hierdie strategie dikwels gebruik om kulturele metafore te vertaal - sulke metafore word dus eintlik in die doelteks geparafraseer in plaas daarvan dat dit met ' $n$ ander metafoor vervang word. ' $n$ Voorbeeld hiervan is "het hy geweet dat hy Kaliel September ver te kort gesaag het" (p. 229), ${ }^{3}$ wat vertaal is met "he realised that he had underestimated Kaliel September".

Venuti onderskei ook tussen twee tipes vertaalstrategieë, naamlik vervreemding (foreignisation) en domestikering. Vervreemding beteken basies dat die vertaler die leser na die skrywer (en die vreemde kultuur) neem deur byvoorbeeld verwysings na die bronkultuur in die doelteks te behou. Die leser is dus bewus daarvan dat hy/sy 'n vertaalde teks uit 'n vreemde kultuur lees, aangesien die kulturele andersheid van die bronteks in die doelteks weergegee word. Dit sluit aan by Newmark (2003:96) se strategie van oordrag, hoewel laasgenoemde hoofsaaklik betrekking het op die oordrag van leksikale items, en Venuti se konsep van vervreemding ook byvoorbeeld sintaksis en vreemde metafoorgebruik insluit.

Volgens Venuti (1995:20) behels vervreemdende vertaling die produksie van 'n doelteks wat doelbewus teen die konvensies van die doeltaal en/of -kultuur indruis deur iets van die vreemdheid van die oorspronklike teks te behou. Hy noem hierdie benadering ook

3 Verwysings waar slegs 'n bladsynommer vermeld word, verwys na Matthee (1985) vir Afrikaanse verwysings en na Matthee (1987) vir Engelse verwysings. 
"weerstand" (resistancy) - 'n nie-vloeiende of vervreemdende vertaalstyl wat daarop gerig is om die teenwoordigheid van die vertaler sigbaar te maak deur die vreemde identiteit van die bronteks te beklemtoon, spesifiek wat vertaling in Engels betref.

Daarteenoor beteken domestikering dat die vertaler die skrywer na die leser neem deur 'n etnosentriese herleiding van die vreemde teks (bronteks) na die kulturele waardes van die doeltaal (Venuti aangehaal in Munday, 2001:146). Laasgenoemde metode behels dat vertaling volgens 'n vloeiende, "onsigbare" styl gedoen word om die vreemdheid van die doelteks vir die doelteksleser te minimiseer. In Fiela's child word in 'n groot mate van hierdie strategie gebruik gemaak. 'n Groot aantal kulturele elemente word byvoorbeeld uit die doelteks weggelaat of deur kultureel neutrale begrippe vervang om die teks so "leesbaar" moontlik vir die doelteksleser te maak.

Volgens Venuti (1995:21) word die hedendaagse Anglo-Amerikaanse kultuur oorheers deur domestikerende teorieë, wat vloeiende vertaling voorstaan, met die gevolg dat tekste wat uit byvoorbeeld Europese of Oosterse tale vertaal word, as 't ware van hulle kulturele identiteit gestroop word. Daardeur word die andersheid wat die vertaling behoort oor te dra, verminder of eenvoudig buite rekening gelaat. Venuti is egter van mening dat 'n vertaling juis die plek behoort te wees waar die leser 'n kulturele andersheid te siene kry, en daardie andersheid kan volgens hom die beste behou word deur 'n "strategie van weerstand" teen domestikering toe te pas (Venuti, 1995:305-306).

Hoewel Venuti (2001:148) 'n voorstander van vervreemding in vertaling is, is hy bewus van die teenstrydighede in hierdie strategie, aangesien dit 'n subjektiewe en relatiewe konsep is wat steeds in die meeste gevalle 'n mate van domestikering behels. Enige kommunikatiewe interaksie (ook vertaling) kan immers net suksesvol wees indien die ontvangers (met ander woorde die doeltekslesers) dit as voldoende koherent met hulle eie situasie - wat hulle kulturele agtergrond insluit - interpreteer (Nord, 1997:32).

\subsection{Bronteks- versus doelteksleser}

Being culture-bound linguistic signs, both the source text and the target text are determined by the communicative situation in which they serve to convey a message. (Nord, 1991:7.)

Die vele kultuurspesifieke woorde en begrippe in Fiela se kind hou verreikende implikasies vir vertaling in. Voordat die vertaler dus so 
'n teks kan begin vertaal, moet hy/sy weet vir wie die bronteks bedoel is en in watter mate hierdie teikengroep ooreenstem met die verwagte doelteksleser.

Hierdie inligting is vir die vertaler belangrik omdat hy/sy die kennis van sekere feite, die herinnering aan sekere ervarings, spesifieke menings en vooroordele, en 'n sekere vlak van linguistiese vaardigheid aan hierdie lesers toeskryf (Coulthard aangehaal in James, 2002:4). Daar moet ook nie vergeet word nie dat die mate waarin die vertaler deur hierdie faktore beïnvloed word, afhang van sy/haar eie sin daarvan om aan 'n spesifieke sosiokulturele groep te behoort (James, 2002:4).

In Fiela se kind korrespondeer die tekswêreld (die "werklikheid" wat in die teks beskryf word) met die bronkultuur. Hoewel die verhaal in die negentiende eeu afspeel, kan die bronteksleser dit in 'n groot mate met sy/haar eie wêreld verbind, terwyl die doelteksleser dit nie kan doen nie. Daar is dus 'n kulturele afstand (Nord, 1991:137) tussen laasgenoemde en die teks, wat 'n invloed het op die effek wat die tekswêreld op hierdie leser het.

$\mathrm{Na}$ aanleiding van James (2002:4) se ontleding van die "ideale leser" kan die volgende gevolgtrekkings oor die "ideale lesers" van Fiela se kind (die bronteks) gemaak word:

\section{- Agtergrondkennis}

Die skrywer veronderstel dat lesers 'n basiese kennis van SuidAfrika se geskiedenis het, onder andere wat die Engelse beheer van die land in die negentiende eeu betref. Verder is die lesers bewus van die verhouding tussen die bruin en wit mense van daardie tyd en die gebrek aan status en mag wat bruin mense gehad het.

\section{- Herinnering aan sekere ervarings}

Die veronderstelde lesers van die Afrikaanse boek het (in sommige gevalle daaglikse) persoonlike kontak met die kultuurgroepe wat in die boek beskryf word - Engelssprekende wit mense, Afrikaanssprekende wit mense en Afrikaanssprekende bruin mense - hoewel natuurlik nie in daardie geskiedkundige tydvak nie. Hierdie lesers kan dus die karakters se optrede, asook die redes daarvoor, in 'n groot mate met bekende gebeure of situasies in die werklikheid verbind. Verder is die idee van die "bosmense" moontlik vir die meeste van hierdie lesers 'n vreemde begrip, terwyl ander aspekte van die lewenswyse in die negentiende-eeuse Suid-Afrika moontlik meer bekend is. 


\section{- Sekere menings, voorkeure en vooroordele}

Die meeste lesers het wel sekere vooroordele ten opsigte van bogenoemde drie kultuurgroepe, dikwels gebaseer op stereotipering. Dit speel 'n rol in die wyse waarop hulle die boek lees en interpreteer.

\section{- 'n Sekere mate van linguistiese vaardigheid}

Die teikenlesers van Fiela se kind kan moontlik met Newmark (2003:13) se "opgevoede middelklasleserskring" vergelyk word.

Die vertaler se eerste groot taak is om 'n nuwe ideale leser vir die doelteks te konstrueer. Al is die doelteksleser van dieselfde ouderdom, geslag en sosiale agtergrond en op dieselfde akademiese, professionele en intellektuele vlak as die oorspronklike bronteksleser, verskil sy/haar kulturele kennis aansienlik van dié van die bronteksleser, omdat hulle aan verskillende linguistiese en kulturele gemeenskappe behoort (Coulthard aangehaal in James, 2002:5; Nord, 1991:24). Dit sal die verwagtings van die doelteksleser en die manier waarop hy/sy die doelteks ervaar, beïnvloed.

Wanneer gekyk word na die kriteria wat gebruik is om die ideale bronteksleser te bepaal, is dit duidelik dat min hiervan op die potensiële doelteksleser van toepassing is. Die volgende gevolgtrekkings kan moontlik oor die "ideale lesers" van Fiela's child gemaak word:

\section{- Agtergrondkennis}

Dit is onwaarskynlik dat al die geskiedkundige en kulturele feite wat aan die brontekslesers bekend is, ook aan die doeltekslesers bekend sal wees. Peter Sabor van die Queen's University in Ontario (1986) skryf byvoorbeeld in 'n resensie van Fiela's child dat Benjamin deur 'n "black family" grootgemaak is. Dit is ook die geval in 'n boekresensie in The New York Times (Graeber, 1992). Die feit dat die skrywers van hierdie resensies bruin mense met swart mense verwar, is moontlik 'n aanduiding van baie doeltekslesers se onkunde in hierdie verband. Doeltekslesers is egter moontlik wel bewus van die rassekwessie in Suid-Afrika - Fiela's child is vir die eerste keer in 1986 oorsee uitgegee, toe verskeie lande sanksies teen Suid-Afrika gehad het as gevolg van die apartheidsregering in die land.

\section{- Herinnering aan sekere ervarings}

Doeltekslesers is oor die algemeen nie bekend met die spesifieke kulturele situasies wat soms indirek beskryf word nie, byvoorbeeld 
deur die gebruik van die aanspreekvorme "baas", "oubaas" en "mies".

\section{- Sekere menings, voorkeure en vooroordele}

Oorsese lesers (veral voor 1994) se bewustheid en interpretasie van die omstandighede in Suid-Afrika met betrekking tot apartheid en rassisme sou hulle siening en interpretasie van die gebeure in die boek ongetwyfeld beïnvloed. Doeltekslesers sal ook instinktief sekere menings, voorkeure en vooroordele vorm deur situasies wat in die boek beskryf word, met hulle eie ervarings te vergelyk, byvoorbeeld wat konfliksituasies tussen bruin en wit karakters betref. In hierdie opsig moet 'n mens onthou dat die doeltekslesers se ervaring van 'n sosiale situasie nie noodwendig ooreenstem met dié van die brontekslesers nie.

\section{- 'n Sekere mate van linguistiese vaardigheid}

Ten spyte daarvan dat die bronteks- en doeltekslesers se vlak van linguistiese vaardigheid moontlik min of meer dieselfde is, sal laasgenoemde se begrip van en reaksie op kultuurspesifieke woorde en begrippe soos "boegoe" (buchu) waarskynlik van dié van die brontekslesers verskil.

\subsection{Kulturele verwysings in die bronteks}

Woorde en begrippe wat kulturele implikasies vir vertaling het, kan geklassifiseer word in terme van onder andere materiële kultuur, ekologie, dialek en taalgebruik, gebare en gewoontes, en geografiese en persoonsname (Newmark, 2003:103). Hierdie aspekte kan op verskillende maniere vertaal word volgens die rol wat dit in die teks vervul (met inagneming van die vertaalstrategie). Die vertaler moet dus besluit hoe belangrik sekere kulturele aspekte is en in watter mate dit nodig of wenslik is om dit in die doeltaal te vertaal (James, 2002:1).

Die situasionele faktore in ' $n$ teks word gewoonlik duidelik in die teksraamwerk genoem, terwyl die interne situasie van 'n fiktiewe teks (met ander woorde die agtergrond en milieu) dikwels net van verskuilde leidrade of indirekte wenke afgelei kan word, byvoorbeeld die eiename van persone en plekke, verwysings na kultuurspesifieke realiteite, en elemente van streeksdialek in die dialoog (Nord, 1991:94).

Die bronteksleser interpreteer hierdie implisiete inligting byna onbewus as gevolg van sy/haar agtergrondkennis oor die bronkultuur, 
maar dit is nie die geval met die doelteksleser nie (Nord, 1991:97). Ander maniere moet dus gevind word om hierdie konnotasies en/of denotasies aan die doelteksleser oor te dra. In sommige gevalle is dit egter baie moeilik om sulke verskuilde inligting in die doelteks te behou, byvoorbeeld met kultuurspesifieke woorde soos "oulap" (p. 9), "Se moer!" (p. 163) of "grootgebring" (p. 275), tensy daar 'n kulturele oorvleueling is tussen die bron- en doeltaal - wat hier nie die geval is nie.

Universele woorde soos "wit" in "hy's safter as ons, want hy's wit" (p. 54) dek wel die universele funksie, maar nie noodwendig die kulturele en geskiedkundige assosiasies wat die bronteksleser daaraan heg nie, byvoorbeeld met betrekking tot die bruin en wit mense se verskillende sosiale posisies in die Suid-Afrikaanse samelewing en die implikasies daarvan (Newmark, 2003:94).

Sulke begrippe kan dus as kulturele verwysings beskou word, omdat die betekenis wat hier ter sprake is, nie bloot semanties van aard is nie, maar kultuurgebonde - dit is betekenis in die konteks van kultuur (Katan, 1999:73). In só 'n geval is dit dikwels nodig om verduidelikende woorde in die doelteks by te voeg, sodat die leksikale funksie en die kulturele konnotasies in die bronteks aan die doelteksleser gekommunikeer kan word (Sapir, aangehaal in James, 2002:8). Dit is egter meestal nie in Fiela's child gedoen nie. Bostaande aanhaling is byvoorbeeld bloot vertaal met: "[H]e's softer than us because he's white."

Die vertaler as kulturele bemiddelaar kan dus soms die hiaat tussen die veronderstelde kulturele en wêreldkennis van die brontekslesers en dié van die doeltekslesers oorbrug deur addisionele inligting te verskaf of aanpassings te maak waar nodig (Nord, 1997:86) om sodoende 'n mate van koherensie te bewerkstellig tussen die doeltekslesers se agtergrondkennis en die inligting wat in die teks gegee word. Dit sal lesers help om in 'n groter mate met die fiktiewe karakters en situasies in die teks te identifiseer (Nord, 1997:88). 'n Voorbeeld waar hierdie strategie met sukses toegepas is, is "sy mahulle se hanskind" (p. 8), wat soos volg hanteer is: "... his parents' hand-child. Like the hand-lamb the ewe does not want that has to be hand-fed."

Die vertaler moet egter bewus wees van die feit dat die verklaring van implisiete inligting, veral in 'n literêre teks, groot veranderings kan veroorsaak ten opsigte van die uitwerking wat die teks op die leser sal hê. Daar is altyd die risiko om die literêre bekoring van die teks in die proses te verloor (Nord, 1991:96, 99). 
Voetnote kan gebruik word om agtergrondinligting of addisionele verduidelikings te verskaf. Die effek wat 'n teks met voetnote op die leser het, verskil egter van dié van 'n teks sonder voetnote. Die vertaler moet dit dus sorgvuldig oorweeg of ander strategieë, byvoorbeeld verduidelikende vertalings, substitusie of selfs 'n woordelys, nie dalk meer geskik sal wees vir 'n spesifieke tekstipe en -funksie as voetnote nie.

In Fiela se kind gebruik die skrywer net een voetnoot, naamlik by "grootvoete" (p. 5), wat die verduideliking "olifante" verskaf. In die vertaling word daar egter nie 'n voetnoot by "bigfeet" verskaf nie, maar wel by "quar" (p. 199), met die verduideliking "type of tree", terwyl die woord "kwar" in die Afrikaanse teks nie deur 'n voetnoot verduidelik word nie. Die keuse van voetnote is dus ietwat vreemd, omdat die bronteks- en doelteksleser in albei hierdie gevalle 'n ewe groot behoefte aan 'n bykomende verduideliking het.

Dit is uiteraard ook noodsaaklik dat die vertaler self die nodige agtergrondkennis moet hê (of verkry) om kulturele verwysings volledig te verstaan voordat hy/sy dit probeer vertaal. In die geval van Fiela se kind is die skrywer van die bronteks en die vertaler dieselfde persoon, met al die nodige kulturele agtergrondkennis wat nodig is vir vertaling. Indien die vertaler egter 'n afsonderlike persoon was, sou sy/haar onkunde oor kulturele en/of geskiedkundige aspekte belemmerend kon wees vir vertaling (Nabokov, 2001:78-79). So 'n persoon sou dus eers navorsing moes doen oor al die relevante onderwerpe wat in die betrokke literêre werk ter sprake kom voordat hy/sy met die vertaling sou kon begin.

Aan die ander kant kan die feit dat Matthee self die boek vertaal het, ook as 'n struikelblok vir die vertaling daarvan beskou word, aangesien sy nie nodig gehad het om weer - vanuit 'n vertalersoogpunt oor die kulturele en geskiedkundige aspekte van die verhaal na te dink nie. Dit het tot gevolg gehad dat sekere vertaalprobleme klaarblyklik sonder inagneming van die teikenlesers van die doelteks hanteer is.

\section{Die hantering van kultuurspesifieke aspekte in Fiela se kind}

\subsection{Materiële kultuur en ekologie}

Verskeie woorde wat spesifieke realiteite van die Suid-Afrikaanse leefwyse benoem, byvoorbeeld "oulap" (p. 9), word in Fiela se kind gebruik. "Oulap" is die naam wat veral ouer mense aan 'n pennie 
gegee het. Dit is dus nie 'n woord wat vandag algemeen deur SuidAfrikaners gebruik word nie. Die vertaler het die keuse gehad om hierdie woord óf net so te behou (vervreemdingstrategie), óf met 'n Engelse vertaalekwivalent te vervang. Sy het besluit om die woord te vertaal (pennies) om sodoende te verseker dat die doelteksleser die begrip sal verstaan. Dit is ook die geval met "die haneboek ... en die Trap der Jeugd" (p. 14), wat met "the first and the second book [of schooling]" vertaal is om die kulturele hiaat tussen die teks en die doelteksleser te oorbrug.

Die begrippe "askoek" (p. 74) en "tiekie se koffie" (p. 239) is verdere voorbeelde van kultuurspesifieke begrippe. Dit is as "ash-bread" en "a tickey's worth of coffee" onderskeidelik vertaal, wat nie die volle betekenis en konnotasies van hierdie konsepte vir die doelteksleser ontsluit nie, byvoorbeeld aangaande die betrokke karakters se sosio-ekonomiese agtergrond. Die kulturele implikasies vir vertaling vereis egter hier dat die begrip eerder volledig begryp moet word as wat die oorspronklike bronteksverwysing beklemtoon word. Die vertaler kon dus moontlik hier eerder 'n begripsomskrywing verskaf het in plaas van die letterlike vertalings "ash-bread" en "a tickey's worth of coffee", omdat min doeltekslesers die agtergrond van hierdie kulturele begrippe ten volle sal verstaan.

'n Ander voorbeeld van 'n kultuurspesifieke realiteit is die woord "bruinvel" (p. 174). Die kulturele kennis wat die bronteksleser (en nie die doelteksleser nie) besit, lei tot 'n onmiddellike reaksie wanneer hierdie woord gebruik word. Ook hier moes die vertaler na aanleiding van die beoogde doelteksfunksie besluit of sy die teks moes uitbrei deur meer inligting oor hierdie negatiewe verwysing na bruin mense (eintlik 'n skeldnaam) by te voeg, en of sy die verwysing heeltemal moes weglaat. Daar is op die neutrale "Coloured woman" besluit, moontlik om linguistiese redes.

Newmark (2003:90) se strategie van kompensering, naamlik om vir betekenisverlies in een deel van ' $n$ sin in ' $n$ ander deel te kompenseer, sou byvoorbeeld hier relevant wees om die negatiewe verwysing na bruin mense elders weer te gee. In Fiela's child word daar egter nie werklik gekompenseer vir die betekenisverlies wat gepaard gaan met die herhaalde vervanging van die woord "bruinvel" deur "Coloured [man/woman]" nie - 'n verskynsel wat ook telkens by ander, soortgelyke gevalle waargeneem word.

Wat plant- en diername betref, het die vertaler in sommige gevalle 'n verduidelikende woord (qualifier) bygevoeg. "Dikkop" in die bronteks (p. 228) se vertaalekwivalent in Engels is byvoorbeeld ook dikkop, 
maar omdat dit 'n inheemse voël van Suid-Afrika is, sal die gemiddelde doelteksleser nie dadelik weet wat met "dikkop" bedoel word nie; daarom het die vertaler hier die verduidelikende woord bird bygevoeg (dikkop bird).

In die geval van "boegoe" (p. 242), 'n inheemse plant wat net in sekere dele van Suid-Afrika voorkom, is die woord bloot as buchu (en elders as bughu) in die doelteks opgeneem, sonder enige verduideliking om die assosiasie wat die bronteksleser met medisyne maak, aan die doelteksleser oor te dra. 'n Verduideliking of omskrywing is in hierdie spesifieke konteks egter nie noodwendig nodig nie, omdat die klem hier op 'n poging tot vervreemding in die teks lê en nie soseer op die medisinale waarde van hierdie plant nie.

Wat die streeksbenaming van plante en diere betref, kan die vertaler ook probleme ondervind indien hy/sy nie deeglike navorsing gedoen het nie. "Tier" (p. 52 en 96) dui in die betrokke konteks byvoorbeeld op 'n luiperd, maar is deel van die algemene (uniek Suid-Afrikaanse) spreektaal. Om "tier" hier met tiger te vertaal (soos in Fiela's child gedoen is) is dus verwarrend vir die doelteksleser, omdat hy/sy aan die dier met strepe sal dink, wat glad nie 'n inheemse dier van SuidAfrika is nie. Dit sou hier dus beter - en inderdaad veel meer korrek - wees om die woord as 't ware te standaardiseer deur dit met leopard te vertaal.

Begrippe of terme wat nie 'n voor die hand liggende Engelse vertaalekwivalent het nie, is soms in die doelteks weggelaat. Die frase "waboom en taaitrek en renosterbos en aalwyn" (p. 10) is byvoorbeeld hanteer deur vertaalekwivalente te verskaf waar moontlik, en die res (taaitrek) in die doelteks weg te laat. Hierdie tipe besluit word gewoonlik na aanleiding van die beoogde doelteksfunksie geneem. In hierdie geval was die weglating van een plantsoort nie werklik van belang nie, omdat die klem eerder val op die opnoem van 'n lys plante. In ander gevalle veroorsaak die blote weglating van woorde of frases wel ernstige leemtes in die doelteks ( $\mathrm{vgl}$. byvoorbeeld 3.2.2).

\subsection{Taalgebruik}

\subsubsection{Dialek en idiolek}

'n Vertaler se hooftaak met betrekking tot die gebruik van verskillende dialekte is om te besluit wat die funksie daarvan is (Newmark, 2003:195). Volgens Newmark behels hierdie funksie(s) gewoonlik die volgende: om 'n informele of sleng taalgebruik aan te 
dui, om die kontras tussen verskillende sosiale klasse aan te dui en/of om plaaslike kulturele eienskappe aan te dui.

In aansluiting hierby is die karakters in Fiela se kind se dialek en idiolek (waaronder woordeskat en samestelling van sinne) 'n implisiete aanduiding van onder andere hulle geografiese herkoms, sosiale stand en agtergrond, intelligensie en opvoedingspeil. Idiosinkratiese spraakvorme, en spesifiek die manifestering daarvan in metaforiese konstruksies (vgl. 3.2.3), word in hierdie roman as 'n sterk karakteriseringstegniek gebruik. Wanneer karakters se eienskappe op sodanige indirekte wyse geïmpliseer word, word van die leser verwag om bepaalde gegewens in die teks te interpreteer met die doel om 'n profiel van elke karakter saam te stel (Kruger, 1990:52). Daarom is 'n realistiese verband tussen die karakter, sy/haar taalgebruik en sy/haar omgewing belangrik.

Die ongeletterde bosmense, wat geografies afgesonderd geleef het en min of geen kontak met die wêreld buite die bos gehad het nie, se taalgebruik is byvoorbeeld plat en sluit baie metaforiese uitdrukkings in wat na die bos verwys. Hierdie idiosinkratiese "bosAfrikaans" word gebruik om die verskil in sosiale stand tussen die sogenaamde beskaafde Hollandse hofamptenare en Engelse aan die een kant en die ongeletterde bosmense aan die ander kant uit te beeld (Kruger, 1990:107). Verder gebruik die skrywer van Fiela se kind verskillende tipes "afwykende" taal by bepaalde karakters om tussen hulle verskillende agtergronde te onderskei. Dit het verskeie implikasies vir die uitbeelding van karakters in die doelteks en daarom is dit belangrik dat die vertaler hierdie aspek van dialoog tydens die vertaalproses in gedagte moet hou.

Newmark (2003:195) is van mening dat die oplossing nie daarin lê om so 'n Afrikaanse dialek met 'n soortgelyke (wat sosio-ekonomiese klas betref) Engelse dialek te vervang nie. Die vertaler moet eerder natuurlike sleng, moontlik "klaslose" spreektaal wat op die dialek sinspeel, matig gebruik, en net 'n klompie van die woorde in die bronteksdialek "verwerk". In aansluiting hierby is die verskillende dialekte van die bruin mense en die bosmense, wat in Fiela se kind 'n uiters belangrike karakteriserende funksie verrig, in Fiela's child grootliks gestandaardiseer.

Dit lei daartoe dat 'n karakter soos Elias van Rooyen deur sy spreekwyse eintlik in 'n hoër sosio-ekonomiese klas geplaas word as in die oorspronklike teks, omdat hy nie meer die plat taal van die bosmense van Fiela se kind gebruik nie. Woorde soos "skippe", "liksens" (p. 3), "oralster", "katel", "loop kyk weer" (p. 4) en "tamteer" 
(p. 112) is byvoorbeeld met die neutrale ships, licence, everywhere, bed, go and look again en be made a fool of onderskeidelik vertaal woorde wat ook algemeen as Standaardengels deur geletterde mense gebruik word.

Ondeurdagte standaardisering van idiosinkratiese taalgebruik kan in sommige gevalle ook 'n verdraaiing van die betekenis tot gevolg hê. Elias se woorde "Opgeskote klong, net so blerrie uit sy pad as sy!" (p. 174) is byvoorbeeld met "A youth, Coloured, as bold as she is!" vertaal. In hierdie geval gaan die ergernis en negatiewe emosie wat met die Afrikaanse teks gepaard gaan, verlore in die vertaling, omdat die Engelse weergawe eintlik byna ' $n$ positiewe stelling is, aangesien bold hier as ' $\mathrm{n}$ positiewe en selfs bewonderenswaardige eienskap geïnterpreteer kan word.

Kruger (1990:78-159) bespreek die hantering van die hoofkarakters se idiosinkrasieë uitvoerig. Dit blyk telkens dat idiosinkrasieë soos Elias se sel-suffiks in byvoorbeeld "maaksel" (p. 32) en Barta se kenmerkende gebruik van die ge-prefiks in byvoorbeeld "geverdwaal en geverhonger" (p. 303) op geen manier in die vertaling weergegee word nie, en dat daar ook geen poging aangewend is om vir die gepaardgaande verlies te kompenseer nie. Die vertaalekwivalente wat gebruik is, verskaf dus geen aanduiding van die spreker se agtergrond nie.

Ook Fiela se spreekwyse word in die doelteks op 'n hoër vlak geplaas deur die standaardisering van haar idiosinkratiese taalgebruik. "Onnooslik" (p. 43), "kooie" (p. 142) en "grootgebring" (p. 275) is byvoorbeeld met onderskeidelik stupid, beds en brought ... up vertaal. Haar taalgebruik verskaf dus geen leidrade aan die doelteksleser oor byvoorbeeld haar sosiale agtergrond of opvoedingspeil nie.

Linguistiese beperkings in die doeltaal speel uiteraard 'n groot rol in die hantering van dialekte en idiolekte. Die gebruik van die woord "lekker" in "[dan] was Kittie nou lekker dood!" (p. 12) is byvoorbeeld tipies Afrikaans en kan nie werklik in hierdie konteks vertaal word nie. Hierdie frase is in die doelteks weergegee as "Kittie would be stone-dead now!", wat beslis 'n mate van verlies meebring wat die vermakerige toon in die bronteks betref. Weereens is geen poging aangewend om hiervoor te kompenseer nie.

Die standaardisering van karakters se taalgebruik in die doelteks lei verder daartoe dat die duidelike onderskeiding tussen verskillende karaktergroepe (byvoorbeeld die bosmense en die bruin mense van 
die Langkloof) vir die doelteksleser verlore gaan. As voorbeeld hiervan gebruik die bruin mense van die Langkloof in die Afrikaanse teks baie meer argaïsmes as die bosmense. Dít kan toegeskryf word aan die feit dat die bosmense byna almal ongeletterd is, terwyl Fiela en haar mense geletterd is en deur die Hooghollandse Bybel wat hulle gereeld lees, beïnvloed word (Kruger, 1990:94). Die vertaler gebruik egter telkens standaardtaalvorme in plaas van argaïese merkers in die doelteks (Kruger, 1990:95) sonder om vir hierdie verlies te kompenseer.

Die skrywer gebruik gereeld die konstruksie "Koos van Sofie" (p. 7) in die bronteks om persone met mekaar te verbind, met die betekenis dat Koos Sofie se man is. Hierdie konsep is kultuurspesifiek omdat dit op die spesifieke manier dui waarop die bosmense aan mekaar gedink en van mekaar gepraat het. Dit is egter nie in die doelteks behou nie, maar gestandaardiseer deur dit met "Sofie's husband, Koos" te vertaal. Die rede hiervoor is moontlik linguisties van aard, naamlik om die Engelse taalgebruik in die doelteks meer idiomaties te maak. Domestikering het dus plaasgevind.

\subsubsection{Tussenwerpsels, uitroepe en aanspreekvorms}

Die emosie wat met kultuurgebonde woorde soos tussenwerpsels en uitroepe gepaard gaan, gaan dikwels verlore in Fiela's child. 'n Voorbeeld hiervan is Fiela se woorde "Se moer!" (p. 163), wat gelaai is met emosionele waarde en twee keer binne 'n kort rukkie geuiter word. Hierdie tussenwerpsel is egter bloot weggelaat in die doelteks sonder om vir die gepaardgaande betekenisverlies te kompenseer, sodat die volle omvang van Fiela se woede en frustrasie nie werklik aan die leser oorgedra word nie. Verder word haar daaropvolgende woorde, "Nou praat jy kak, Petrus Zondagh!", ook ietwat afgewater deur die neutrale "That's nonsense, Petrus Zondagh!".

Ander kru taalgebruik van Fiela in die bronteks word ook óf weggelaat in die doelteks óf met 'n neutrale uitdrukking vervang, wat die doelteksleser se karakterprofiel van Fiela ongetwyfeld sal beïnvloed. Fiela se kras of plat taalgebruik het juis ten doel om haar as ' $n$ reguit mens wat nie doekies omdraai nie, uit te beeld (Kruger, 1990:117). Deur plat uitdrukkings soos "kaalgat" in "[d]ie Komoeties was wel arm, maar hulle was nie kaalgat nie" (p. 57) met die neutrale penniless te vertaal, word Fiela se karakteruitbeelding dus eintlik verwring, sodat die Fiela van Fiela's child uiteindelik nie dieselfde mens is as dié van Fiela se kind nie. Dieselfde geld ook ander karakters, byvoorbeeld Elias en Nina. 
Die manier waarop karakters mekaar aanspreek, is kultuurgebonde. Dit is interessant dat hoewel ma en pa in Fiela's child behou word, "oom" met uncle vertaal word, hoewel uncle nie in die werklike lewe op dieselfde manier gebruik word as "oom" nie - Afrikaanssprekende kinders spreek dikwels byna enige vreemde man as oom aan, terwyl Engelssprekendes normaalweg net 'n familielid (hulle pa of ma se broer of swaer) as uncle aanspreek. Die vertaler was dus hier om die een of ander rede nie konsekwent met die toepassing van die oordragstrategie nie.

Die gebruik van die aanspreekvorme "mies" (p. 67) en "baas" (p. 51) is tipies Suid-Afrikaans en dui daarop dat die bruin mense in Fiela se kind tot 'n laer sosiale klas as die wit karakters (selfs die bosmense) behoort. In die bronteks word 'n verdere onderskeid tussen "baas" en "oubaas" getref - laasgenoemde dui ook op 'n mate van respek vir 'n ouer persoon. Albei hierdie terme word in Fiela's child met master vertaal wanneer dit in die tweede persoon gebruik word, sodat die doelteksleser nie eens bewus is van die feit dat daar in Afrikaans twee verskillende aanspreekvorme is nie. Met die oog op die funksie van die doelteks is die gepaardgaande "verlies" in hierdie geval egter nie werklik van belang nie.

\subsubsection{Metafore}

Volgens Van Vuuren (1987:7) gebruik Matthee die taal van die karakters in Fiela se kind om vorm aan die wêreld van die bos, die Langkloof en die see te gee. Die taalgebruik van die mense in elkeen van hierdie drie wêrelde weerspieël die aktiwiteite waarmee hulle daagliks besig is, en veral die konkretisering van abstrakte gevoelens en emosies vanuit hulle leefwêreld, die bos-, plaas- of seelewe, is volgens Van Vuuren opvallend. Laasgenoemde dra by uitstek daartoe by om hierdie karakters se eenvoud en ongekunsteldheid uit te beeld (Kruger, 1990:113; Van Vuuren, 1987:8).

Volgens Kruger (1990:109) is dit juis as gevolg van hierdie interafhanklikheid tussen die karakters, hulle taalgebruik en hulle omgewing dat Matthee daarin slaag om die karakters in Fiela se kind oortuigend aan te bied. Hierteenoor het die inkonsekwente vertaling van byvoorbeeld metafore in karakters se dialoog of gedagtetaal belangrike implikasies vir die leser se interpretasie van die teks as geheel, omdat metafore dikwels deel uitmaak van 'n groter netwerk van beelde. 'n Versteuring van só 'n netwerk kan die karakteruitbeelding en -egtheid in die doelteks beperk, aangesien dit daartoe kan lei dat sentrale karaktereienskappe nie vir die doeltekslesers onderskei kan word nie. 
Wat Fiela's child betref, veroorsaak die standaardisering van karakters se idiosinkratiese taalgebruik en die parafrasering van vele metafore dat die karakteruitbeelding in hierdie teks ernstige skade ly. Fiela se karakter is byvoorbeeld geloofwaardig in die bronteks juis omdat haar metaforiese taalgebruik uit haar ervaringswêreld kom en dus haar daaglikse aktiwiteite weerspieël. Dit het tot gevolg dat die bronteksleser haar as eg menslik en aards ervaar (Kruger, 1990:118). Dieselfde kan egter nie van die ooreenstemmende doeltekskarakter gesê word nie, aangesien baie van haar eienskappe wat in die bronteks deur haar taalgebruik geïmpliseer word, in die vertaling verlore gaan deur die parafrasering van haar metaforiese uitdrukkings. Fiela se uitsonderlikste karaktereienskap, naamlik haar leefwyse as boer- en huisvrou, ontbreek in die vertaling, en haar karakter toon nie meer dieselfde egtheid as in die bronteks nie, omdat die sosiolinguistiese verband tussen haar karakter, taalgebruik en omgewing nie meer in die doelteks bestaan nie (Kruger, 1990:172, 183). Hierdie voorbeeld illustreer Kruger (1990:22) se stelling dat metafore in die bronteks nie sonder verlies aan betekenis in die vertaling geparafraseer kan word nie.

Kruger (1990:160-202) se diepgaande ondersoek ten opsigte van die karakterisering van die hoofkarakters deur hulle metafoorgebruik kan as bron van verdere voorbeelde in hierdie verband gebruik word. Uit Kruger se bespreking is dit duidelik dat die netwerk van beelde waarvan die talle metafore in Fiela se kind 'n onontbeerlike deel uitmaak, inderdaad in die doelteks versteur word. Die gevolg hiervan is dat die karakteruitbeelding en -egtheid van die meeste karakters in Fiela's child drasties beperk word, sodat die karakters in die doelteks nie meer ten volle ooreenstem met dié in die bronteks nie.

Kruger (1990:200-201) bespreek ook die gevolge van die feit dat die karakters in die doelteks standaardtaalsprekers word soos die verteller. Dit veroorsaak dat hulle nou selde deur middel van hulle onuitgesproke gedagtes uitgebeeld word, aangesien persoonsteks vertellersteks word. Dit is ongetwyfeld 'n groot leemte in Fiela's child, aangesien die individualisering van die karakters in die bronteks dikwels in die vorm van die vrye indirekte rede in die persoonsteks plaasvind.

\subsection{Geografiese en persoonsname}

Byna al die name van die karakters word in die doelteks met die Afrikaanse spelwyse behou, byvoorbeeld Dawid en Sofie, wat 'n mate van vervreemding in die doelteks bewerkstellig. Daar is egter 
enkele uitsonderings, byvoorbeeld "Krisjan Smal" (p. 2), wat in die doelteks met die Engelse spelwyse (Small) geskryf word, en "Goliat" (p. 90) wat Goliath word. Die vertaler was dus nie in hierdie opsig konsekwent nie.

Die een volstruis se naam, "Skopper", is met Kicker vertaal. Hier is kulturele aanpassing gedoen om die effek van ekwivalensie te verkry (Nord, 1997:53) en daardeur die betekenis van die naam vir die doelteksleser duidelik te maak.

Wat geografiese name betref, word die Engelse vertaalekwivalent meestal gegee, byvoorbeeld Lily Valley Bush vir "Lelievleibos". Daar is egter enkele name, byvoorbeeld Draaikloof, wat in die vertaling behou word. Die rede hiervoor is waarskynlik dat sodanige name nie 'n voor die hand liggende Engelse vertaalekwivalent het nie.

Daar is dus 'n opvallende gebrek aan konsekwensie wat betref die hantering van geografiese en persoonsname. Hoewel Newmark se strategie van oordrag in sommige gevalle gebruik is, is Engelse ekwivalente vir eiename ook dikwels gebruik.

\section{Slot}

Deur die strategie van oordrag (Newmark, 2003:96) is sekere kulturele elemente van Fiela se kind in die vertaling behou om die doelteksleser as 't ware na die Knysnabos te probeer bring. Ten spyte van hierdie poging tot vervreemding is dit egter duidelik dat dit die vertaler se grootste prioriteit was om te probeer verseker dat die inhoud en taal wat in die brontekskonteks teenwoordig is, ten volle aanvaarbaar en verstaanbaar sou wees vir die doeltekslesers, wat 'n algemene strategie van domestikering vereis het. Idiosinkratiese taalgebruik en metaforiese konstruksies uit die plaas- en boslewe is in die vertaling meestal geparafraseer of bloot weggelaat (Kruger, 1990:197). Dit het noodwendig daartoe bygedra dat die linguistiese verskeidenheid en kreatiwiteit in Fiela's child verminder is.

Kruger (1990:198) is van mening dat konkretisering deur middel van metaforiese konstruksies in idiosinkratiese spraakvorme, wat in Fiela se kind 'n uiters belangrike karakteriseringstegniek is, in die vertaalproses verlore gegaan het. Die eenvoud, ongekunsteldheid en eg menslikheid wat tipies is van die karakters in die bronteks, word volgens Kruger (1990:201) in die vertaling afgewater tot slegs 'n flou weerkaatsing van die oorspronklike karakters. Dit het tot gevolg dat die geslaagdheid van Fiela's child as literêre werk in die gedrang kom, veral wat karakteruitbeelding betref. Hierdie waarne- 
ming beklemtoon die geldigheid van Kruger (1990:77) se stelling dat spraakvorme as 'n aspek van narratiewe struktuur nie in isolasie vertaal kan word nie.

Daar moet egter ook onthou word dat die moontlikheid om te vertaal, nie totale vertaalbaarheid veronderstel nie (Van den Broeck \& Lefevere aangehaal in Kruger, 1990:130). As gevolg van strukturele verskille tussen tale en kulture sal die verhouding tussen 'n bronteks en die vertaling daarvan nooit volkome een tot een kan wees nie. Daar sal dus altyd in 'n meerdere of mindere mate verlies aan betekenis wees (Kruger, 1990:131; Newmark, 1981:7). Veral kultuur- en persoonsgebonde taalgedragsvorme soos dialekte en sosiolekte is dikwels moeilik oordraagbaar van een taal na 'n ander (Kruger, 1990:151). Daar moet toegegee word dat Matthee in hierdie verband wel voor talle moeilik oorkombare probleme te staan gekom het.

Tog blyk dit dat sekere faktore, byvoorbeeld inkonsekwensie ten opsigte van die hantering van vertaalprobleme en moontlik selfs 'n gebrek aan 'n vooraf bepaalde vertaalstrategie, tydens die vertaling van Fiela se kind veroorsaak het dat verlies soms onnodig plaasgevind het. Die kulturele konteks en die interafhanklikheid van die intratekstuele komponente is ook skynbaar nie altyd in gedagte gehou nie. Gevolglik het beduidende betekenisverlies dikwels plaasgevind sonder dat gepoog is om op 'n direkte of indirekte wyse daarvoor te kompenseer. Matthee se hantering van vertaalprobleme op mikrostrukturele vlak het oënskynlik meestal ten doel om die teks so verstaanbaar moontlik vir die doeltekslesers te probeer maak, maar dit het ongetwyfeld makrotekstuele semantiese verskuiwings (Kruger, 1990:142) in die doelteks teweeg gebring. Matthee het dus nie daarin geslaag om haar rol as kulturele bemiddelaar op alle vlakke van die teks suksesvol te vervul nie.

Daar word tot die slotsom gekom dat die vertaling as gevolg van 'n gebrek aan kulturele bemiddeling nie ten volle as literêre werk slaag nie. Eerstens het onontbeerlike karakteriseringstegnieke in die vertaalproses verlore gegaan, en die karakters word nie meer as lewensgetrou en geloofwaardig ervaar nie - hulle het uiteindelik "afwykende mutante" (Kruger, 1990:201) van die brontekskarakters geword. Tweedens toon die doelteks nie meer dieselfde linguistiese rykheid en kleur wat kenmerkend is van Matthee se skryfstyl nie, en derdens sal doeltekslesers baie kultuurspesifieke verwysings wat sonder meer deur middel van Newmark se oordragstrategie in die doelteks opgeneem is, in elk geval nie ten volle verstaan nie, en in sommige gevalle waarskynlik glad nie. Vierdens bring inkonsekwen- 
te vertaling mee dat verskeie leemtes in die doelteks ontstaan, onder andere as gevolg van versteurde intratekstuele netwerke.

'n Vervreemdende benadering tot die teks as geheel sou moontlik meer suksesvol wees. Doelbewuste weerstand (Venuti, 1995:305306) teen domestikering sou doeltekslesers daarvan bewus maak dat hulle 'n vertaalde teks uit 'n vreemde kultuur lees, en hulle sou gevolglik waarskynlik ook meer ontvanklik wees vir kulturele andershede in die teks. As gevolg van die groot kulturele afstand tussen die bronteks- en doeltekslesers sou voetnote, of dalk eerder 'n woordelys, waardevol wees om die betekenis en gepaardgaande assosiasies van kultuurspesifieke begrippe aan die doeltekslesers te ontsluit. In gevalle waar linguistiese beperkings in die doeltaal beperkings plaas op die hantering van metafore of tussenwerpsels, behoort die vertaler op die een of ander wyse daarvoor te kompenseer sodat betekenisverlies in die doelteks geminimaliseer word. Op hierdie manier sou die vertaler waarskynlik meer getrou aan sy/haar rol as kulturele bemiddelaar wees.

\section{Geraadpleegde bronne}

GRAEBER, L. 1992. New \& noteworthy. The New York times, 20 Sept. http://query.nytimes.com/gst/fullpage.html?res=9E0CE4D61E38F933A1575AC0 A964958260\&sec=\&spon=\&pagewanted=2 Date of access: 6 Jul. 2007.

JAMES, K. 2002. Cultural implications for translation. Literary translations, 6(4), Oct. http://accurapid.com/journal/22delight.htm Date of access: 14 Mar. 2006.

KATAN, D. 1999. Translation cultures: an introduction for translators, interpreters and mediators. Manchester: St. Jerome.

KRUGER, A. 1990. Die vertaling van idiosinkratiese vorme van spraak in narratiewe fiksie, met spesiale verwysing na Fiela se kind. Pretoria: UNISA. (M.A.-verhandeling.)

MATTHEE, D. 1985. Fiela se kind. Kaapstad: Tafelberg.

MATTHEE, D. 1987. Fiela's child. Johannesburg: Penguin.

MUNDAY, J. 2001. Introducing translation studies: theories and applications. London: Routledge.

NABOKOV, V. 2001. Problems of translation: Onegin in English. (In Venuti, L., ed. The translation studies reader. London: Routledge. p. 71-83.)

NEWMARK, P. 1981. Approaches to translation. Oxford: Pergamon.

NEWMARK, P. 2003. A textbook of translation. 2nd ed. Harlow: Pearson Education.

NORD, C. 1991. Text analysis in translation: theory, methodology, and didactic application of a model for translation-oriented text analysis. Amsterdam: Rodopi.

NORD, C. 1997. A functional typology of translations. (In Trosberg, A., ed. Text typology and translation. Amsterdam: Benjamins. p. 43-66.) 
SABOR, P. 1986. Editorial review: Matthee, Dalene - Fiela's child. Library journal, 15 May. http://www.amazon.com/Fielas-Child-Dalene-Matthee/dp/ 0394552318/ref=dp_return_2/104-51485732902368?ie $=$ UTF8\&n=283155\&s= books Date of access: 6 Jul. 2007.

VAN VUUREN, H. 1987. Fiela se kind. Pretoria: Academica. (Blokboek, 54.)

VENUTI, L. 1995. The translator's invisibility: a history of translation. London: Routledge.

VENUTI, L. 2001. Translation, community, utopia. (In Venuti, L., ed. The translation studies reader. London: Routledge. p. 468-488.)

\section{Kernbegrippe:}

interkulturele kommunikasie

kulturele bemiddelaar

Matthee, Dalene

vertaalprobleme

vertaler

\section{Key concepts:}

cultural mediator

intercultural communication

Matthee, Dalene

translating problems

translator 
